\title{
Cross-cultural information for Japanese nurses at an international hospital: a controlled before-after intervention study
}

Mariko Nishikawa ( $\square$ mn378@nyu.edu )

University of Human Environments https://orcid.org/0000-0001-9976-688X

Masaaki Yamanaka

Japan Coast Guard Academy

Akira Shibanuma

The University of Tokyo

Junko Kiriya

The University of Tokyo

Masamine Jimba

The University of Tokyo

Research article

Keywords: Digital cartoon, cross cultural information, foreign patient, Nurse, Japan

Posted Date: November 24th, 2020

DOl: https://doi.org/10.21203/rs.3.rs-79484/v1

License: (a) This work is licensed under a Creative Commons Attribution 4.0 International License.

Read Full License 


\section{Abstract}

\section{Background}

Overseas visitors to Japan steadily increased for a decade until the pandemic of 2020. In 2019, 31.8 million people visited the country due to an easing of restrictions and an emphasis on tourism. Nurses are the forefront of the healthcare system when they interact with those overseas visitors at a clinic or hospital. The goal of this study is to evaluate the efficacy of providing health information, through an ordinary travel guidebook or a short digital cartoon by measuring the anxiety level of Japanese nurses who deal with foreign patients.

Method

Our approach involves a controlled before-after intervention study from January to March in 2016 at a major international hospital in Japan. We surveyed nurses at three wards of the hospital who understood English and cared for foreign patients as the 1 st intervention group. Following which, we collected data from the same 1st intervention group, but now considered as the 2 nd intervention group. Nurses in the 1 st intervention group read health information in a travel guidebook for Japan. Nurses in the 2nd intervention read health information in the guidebook and watched a four-minute digital cartoon in English on health services in Japan, titled Mari Info. After each intervention, the nurses answered a self-questionnaire, wherein we assessed their level of anxiety to care for foreign patients. We evaluated the results through statistical testing and the State-Trait Anxiety Inventory Form Y (STAI-Y).

Results

Of 111 nurses, 83 (74.8\%) completed both interventions and a questionnaire. Reading the guidebook as well as watching a digital cartoon, as the 2 nd intervention was more effective in reducing the level of anxiety to care for foreign patients compared to reading only the guidebook.

\section{Conclusions}

Japanese nurses can lower their anxieties on dealing with foreign patients by knowing the various forms of healthcare information currently accessible to overseas visitors in both guidebooks and digital content. This helps them learn the ethical concerns and cultural norms of foreign patients they might care for.

\section{Background}

The number of overseas visitors to Japan surpassed the number of Japanese nationals traveling to foreign countries since 2015 [1, 2]. Overseas visitors increased 21.4\%, from 24 million in 2016 to over 31.8 million in 2019 , orchestrated by a successful government strategy [2] until the closing of the border due to the COVID-19 pandemic[1]. In 2019, the government of Japan passed legislation permitting longer temporary work-permits for both skilled and unskilled foreign workers, to compensate for a decline in the working-age population. These factors as well as the 2021 Tokyo Olympic and Paralympics games are 
expected to increase the number of short and long-term overseas visitors to Japan [2-4]. A concomitant increase in overseas patients to Japanese health facilities can be expected with the increase in visitors and expatriates. Common ailments amongst foreigners that visit health facilities are signs of fever, bruises, nausea, abdominal pain, or diarrhea $[5,6]$. In extreme cases, they require hospital stays and an operation $[7,8]$.

The provision of quality care by nurses to foreign patients involves language of communication, payment, and access to the patients' medical history [9-11]. Providing cross-cultural information to health care workers helps them make foreign patients feel more at ease [12-14]. Nurses in most countries are less likely to have the cross-cultural education, information or training. An exception is Switzerland, a developed country where multinational people work together [15]. Since nurses work with patients more closely, as is the nature of their profession, ethical concerns and the foreign patient's wishes appeared as the most important to both nurses and foreign patients [13].

Nurses in Japan deal with three main areas of concern whilst taking care of overseas patients. They are: medical expense, informed consent and language of communication [16]. Sufficient cultural education could reduce the nurses' concerns [16] and lead to culturally sensitive care[17].

A review of literature [18-20] identified three critical concerns for nurses. Language skills training in intercultural healthcare communication was the first concern. The nurses were not confident of their cross-cultural skills in a second language. Nurses in Austria needed special training to develop language and cultural skills[18]. The provision of information on cross-cultural care competency is the second concern. This is true for the Arabic population in the United States. Culturally and linguistically appropriate guidelines were useful to shorten the gap between Arabic and western cultures to facilitate healthcare needs [19]. Cross-cultural education for nursing students was the third concern. For example, courses in the United States, include a study-abroad program in a developing country to understand customs, living condition and health institutions. Those who participated in these programs reported improved cross-cultural skills in their profession [20].

A digital cartoon is a simple way to educate patients with disabilities, such as dementia [21]. An earlier study showed that an educational digital video of washing hands with soap in India, improved the sanitation level of households[22]. Internationally, other examples of patient education and healthcare provider training, by digital cartoons include the improvement of health literacy for self-care among older Australians [23], and about insulin therapy for diabetes in England [24].

We created a digital cartoon movie, called Mari Info Japan to inform overseas visitors about the health system in Japan[25, 26]. However, the effectiveness of providing cross-cultural information through an ordinary guidebook and a digital cartoon to nurses has not been explored. This education method can be applied to convey information on cultural-skills training to nurses.

The objective of our study is to investigate the effectiveness of reducing anxieties for Japanese nurses who care for foreign patients in Japan. Our hypothesis is Japanese nurses can reduce their level of 
anxiety dealing with foreign patients after reading an ordinary guidebook and watching the digital cartoon on culture and behavior.

\section{Methods}

\section{Setting}

We performed this research at an international hospital in the city of Kobe, Japan. We chose this hospital due to its history and location. Kobe is an international seaport with a history of foreign settlements. The hospital was established by a German doctor in 1871[27]. It has since been treating seamen, diplomats and migrants from the Far East and western countries for decades. Today, the hospital has a unique international internal medicine outpatient unit, staffed by medical doctors and nurses fluent in English. Approximately 200 foreign patients visited to the hospital each month in 2014. Most of them were English speakers. Seventy percent of the foreign patients were migrants to Japan while the remaining thirty percent were short-term overseas visitors.

The nurses who worked at the hospital dealt with foreign patients on a daily basis. Two thirds of the Japanese nurses (120 out of 180) could read and correspond in English. Some of them spoke another foreign language such as French or Mandarin. Many nurses wore a badge depicting the country flags of the language they could speak. All nurses were born in Japan and held Japanese nationality in this study. We chose this hospital because all 180 nurses regularly dealt with foreign patients and 120 of them clearly understood our research interventions in English.

\section{Study design and procedures}

We performed a controlled before-after intervention study [28]. We had two components of the interventions: one with an ordinary travel guidebook popular with overseas visitors; the other was the same travel guidebook and a digital cartoon. In this controlled before-after intervention study, we evaluated the anxiety-level of nurses at the international hospital from January to March in 2016. The nurses responded to our question about their level of anxiety before receiving either intervention. After each intervention, the nurses responded to the same questions to assess, if their anxiety-level changed. We examined the difference in anxiety pre and post intervention, and between the $1^{\text {st }}$ intervention, the $2^{\text {nd }}$ intervention and the 1 st intervention + the $2^{\text {nd }}$ intervention, and between the $1^{\text {st }}$ intervention vs. $2^{\text {nd }}$ intervention, and the $1^{\text {st }}$ intervention vs. the $1^{\text {st }}$ intervention + the $2^{\text {nd }}$ intervention. The interventions were conducted within one month.

\section{Participant entry}

\section{Sample size}

In order to achieve a confidence level of $95 \%$ and $80 \%$ power to detect a difference of 0.2 , we calculated that a sample size of 80 nurses is necessary. 


\section{Eligibility}

We contacted Japanese nurses aged twenty and higher, who could read and listen to English at three out of six wards. The questionnaire was only in Japanese to avoid any difference in interpretation. This ensured they could understand and concentrate on their responses in their first language.

\section{Enrolment procedure}

Subsequently we enlisted all eligible nurses who understand English at three wards. It was difficult to introduce both the $1^{\text {st }}$ intervention and $2^{\text {nd }}$ intervention to them at the same time while avoiding crossing intervention at this small international hospital. We first sampled the nurses as the guidebook-reading group. Within one month those same nurses participated at the same wards as the digital cartoon watching group. We enlisted nurses based on their readiness to divulge their feelings of dealing with overseas visitors within the Japanese healthcare system.

\section{Interventions}

We provided a short explanation on how to use the digital cartoon at nursing committees after which, the nurses answered the questionnaire without any assistance or interference.

\section{$1^{\text {st }}$ intervention procedure}

The nurses who participated our research read a brief information piece in English from an ordinary travel guidebook [29] (additional file 1).

\section{$2^{\text {nd }}$ intervention procedure}

Within one month, the same nurses viewed a four-minute digital cartoon named Mari Info Japan in English (additional file 2) as the $2^{\text {nd }}$ intervention group. This cartoon provided information to foreign patients on the healthcare system in Japan. It dealt with the main concerns of foreign patients [12]. It comprised of eleven points succinctly presented with music [26]. The nurses used an $8 \times 5$-inch digital notepad with headphones to watch the cartoon.

\section{Outcome assessment}

Pre- and post-intervention, we examined the level of anxiety by measuring the Mari Meter- $X$ (additional file 3) and STAI-Y.

1. Mari Meter- $X[16,26]$ analyzes the anxiety-level of nurses when taking care of foreign patients in Japan. It is a five-point Likert-type scale with a 15 -item questionnaire. The total score ranged between 15 to 75 points. A high score indicates greater anxiety.

2. STAI-Y [30] is a questionnaire that uses a four-point Likert-type scale and consists of 40 items. The questions separate into two parts. The first half consist of questions asking about their state anxiety, 
the second half about their trait anxiety. State anxiety is the level of anxiety felt when taking care of foreign patients, the level of anxiety experienced in their daily is described by trait anxiety. Before the intervention, the nurses answered the questions regarding both state and trait anxiety. After the $1^{\text {st }}$ and 2nd intervention, the nurses reported only their state anxiety. The STAI-Y scores (lowest 40highest 160$)$ are divided into state anxiety (20-80 points) and trait anxiety (20-80 points). In both cases, a high score implies more anxiety.

\section{Other information}

As this was a controlled before-after intervention study, we gathered demographic data. This included their age, gender, profession, educational level, working experiences, current position, and ward of work (table 1). The nurses took about fifteen minutes to answer all questions. The nurses could choose a convenient time to participate in this study.

\section{Bias prevention}

The nurses were not told if they were either in the $1^{\text {st }}$ intervention or the $2^{\text {nd }}$ intervention period. The researcher who analyzed the data was not blind to the results.

\section{Data analysis}

For the primary outcome, we selected a non-parametric statistic because Levene's test was statistically significant $(p<0.05)$ in non-paired groups. We examined the difference in median scores for the Mari Meter- $X$ and STAI-Y state anxiety before and after the intervention for each group with a two-sided Wilcoxon signed rank test. Conducting a Wilcoxon rank sum test, we analyzed the differences of the calculated scores both between groups and between pre- and post-intervention. All statistical evaluations were performed with the help of the JMP statistical package (version 11.0).

\section{Results}

111 nurses agreed to participate in the study. We eliminated data from 28 nurses who did not complete either interventions or the questionnaire because the nurses became unavailable during the intervention (13 in the 1 st intervention and 15 in the 2 nd intervention) questionnaires contained incomplete data (Fig. 1). We collected and analyzed the data from a total of 83 nurses. The participants were the same in both interventions to assure consistency across the experiment.

\section{Characteristics of nurses}

An overview of the basic features of the participating nurses $(n=83)$ is given in Table 1. The mode of age lays within the 30-40-year bracket. Most of the nurses were female (92.8\%) and held a Registered Nurse (RN) qualification (97.6\%). Over half of the nurses held a three-year RN diploma (62.7\%). None of them took cross-cultural nursing courses. The average duration of working experience was 12.8 years. Four out 
of five nurses were working as staff. Most of the nurses were working at an inpatient unit when they participated in this study.

\section{Reliability of outcomes}

We calculate Cronbach's alpha internal consistency reliability coefficient to assess the reliability of the measures used in this study. The Mari Meter- $X$ gave a reliability of 0.88 , while the STAI-Y yielded 0.91 .

\section{Change in the level of anxiety}

Table 2 shows both the general feeling the nurses had before the interventions and the change induced by them. The former is indicated by the 25th (41), 50th (46), and 75th (53) percentiles out of the maximum 80 points in the STAI-Y trait anxiety scores. The change in anxiety is shown by the Wilcoxon signed rank tests pre- and post-intervention. In the 1 st intervention group, the Mari Meter- $X$ score did not change significantly (median changed from 59 to $58 \square p=0.151$ ) after the intervention, whereas the STAI-Y state anxiety score changed significantly (median changed from 47 to $45, p<0.001$ ). A statistically significant reduction in the Mari Meter- $X$ score before and after the intervention was observed in the $2 n d$ intervention group (median changed from 59 to 52, $\mathrm{p}<0.001$ ). Similarly, the reduction in STAI-Y state anxiety scores before and after receiving the 2 nd intervention was statistically significant (median changed from 55 to $51, p<0.001)$. A statistically significant reduction in the Mari Meter- $X$ score before and after was observed in the combined 1st +2 nd intervention group (median changed from 59 to $52, p<$ 0.001). It implies that the nurses understood the needs of overseas visitors from their cross-cultural education. However, the induction in STAI-Y state anxiety scores before and after receiving the $1 \mathrm{st}+2 \mathrm{nd}$ intervention was statistically significant (median changed from 47 to $51, p<0.01$ ).

Table 3 shows the comparison in the change in scores between the two groups by Wilcoxson rank sum test. The Mari Meter- $X$ score was more reduced in the 2 nd intervention group than in the 1 st intervention group (median: 2 and 0 , respectively, $\mathrm{p}<0.01$ ). The STAI-Y state anxiety was same in the 1 st intervention group and 2nd intervention group (median: 2 and 2, respectively, $p=0.088$ ). There were no factors included in this study that affected the outcome because it was a controlled before-after intervention study with the same participants.

Table 4 indicates the contrast in the shift in scores between the two groups by Wilcoxson rank sum test. The Mari Meter- $X$ score was further diminished in the combined $1 \mathrm{st}+$ the 2 nd intervention group than only in the 1st intervention group (median: 0 and 7, respectively, $p<0.001$ ). However, the STAI-Y state anxiety was different in the 1st intervention group and the 1st + the 2nd intervention group (median: 2 and - 2, respectively, $p=0.003$ ). One factor that may have affected the outcome was that the head nurse of the hospital suddenly changed. It is unclear if this would affect the outcome.

\section{Discussion}

This study showed that the ordinary guidebook and the digital cartoon reduced concerns of Japanese nurses who care for foreign patients. The information is related to the Japanese health system and 
illness prevention (measured with Mari Meter-X), however the intensity of feelings of nervousness (measured with STAI-Y) was not for the nurses.

Our results were similar to a previous study confirming the advantages of providing succinct health information for international visitors to Japan [26]. People with dementia may have health needs but have limited language capacity. In this situation, a digital cartoon that provides guidance was found to be the most helpful [21]. In the same manner, an educational DVD was found to reduce anxiety in women diagnosed with gestational diabetes mellitus in UK[31].

The main finding confirms that reading an ordinary guidebook and watching a digital cartoon provides nurses knowledge of what foreign visitors to the country know about the Japanese health system. The ordinary guidebook and digital cartoon combination is more effective as it provides basic information about health promotion, accessing health services for overseas visitors in Japan. None of the nurses who worked at the international hospital had taken any cross-cultural nursing courses. However, the anxietylevel of the nurses improved after they were made aware of the information available to international patients [32]. This made the nurse more comfortable to provide information on the next step to foreign patients.

This is still uncommon for nurses in a homogenous society like Japan to learn about foreign customs. The hospital in this study has a unique history established by foreign doctors for foreign patients. It may focus on clinical satisfaction for the patients as well as their health. Only limited studies and tools are available related to information requests from overseas visitors.

For the first time, this research evaluates the effectiveness of an ordinary guidebook and a digital cartoon for nurses of Japanese health information for foreign patients in Japan on the requests from overseas visitors. Another strength is, that we could perform the study at an international hospital in Japan where the nurses cared for foreign patients daily and were proficient in English. Consequently, their opinions are more realistic. Third, the study focuses on assessing interventions from unknown overseas visitors' basic requests. Lastly, this study has a moderately high participation rate of $93 \%$ (111 out of 120). Targeting those who were working at the hospital provides more knowledge to other workers.

This research also has certain limitations. First, the research setting was limited. Our research design was a controlled before-after intervention study, which could not make a comparison group. Second, we were not certain if the participants were blind to their interventions even though we tried. Furthermore, the research assistants who directed the data collection and data analyses were not blinded to the intervention. Third, we could not randomly assign participants to groups, which means that we had only one group for evaluating the effect of the intervention for other factors that could affect the outcome. Unspecified factors will be still existed, such as remaining effects from 1st intervention and how working environments might affect the results. The head nurse who was the vice president of the hospital changed between the 1st and 2nd intervention. It might emotionally affect the nurses. However, we could not examine if this or other factors are due to a single group study in a unique hospital setting. 


\section{Implications and future study}

Our findings demonstrate the benefits of delivering health-related information with feedback from foreign patients to nurses through a simple but comprehensive way. Furthermore, we want to constantly assess the actual content of educational material is, that is necessary the nurses taking care of foreign patients, based on recent events. Examples include web learning and use of smart-phone applications.

Future research on ways to introduce this kind of information to nurses at a convenient time for the nurses might be important. This study will not generalize the results. We believe that this research setting was unique compared to other hospitals in Japan. This study needs a randomized controlled trial (RCT) to introduce stronger evidence for the effectiveness of the intervention and at the same time avoid unspecified confounding factors.

\section{Conclusions}

We found that reading an ordinary guidebook combined with watching a digital cartoon, is more efficient in decreasing anxiety among Japanese nurses who deal with foreign patients, compared with only reading an ordinary guidebook. The nurses recommended that overseas visitors should know the main points about the health system in Japan as summarized by the digital cartoon (Mari Info) before entering the country. The information provided by short cartoon is a convenient heuristic method. Providing similar digital cartoons of health information is valuable for hospitals to enhance the anxiety-level of nurses and to understand foreign patients in Japan.

\section{Abbreviations}

RN: Register Nurse; STAI-Y:The State-Trait Anxiety Inventory Form-Y; NRS:non-randomized controlled study; RCT:randomized controlled trial.

\section{Declarations}

\section{Ethical approval and consent to participate}

The Ethics Committee of University of Human Environments (UHE) approved the research design of this study on December 2015 (approval number uhe-2015005). Oral informed consent was received from all nurses prior to the 1 st intervention. The Ethics Committee of UHE permitted oral informed consent.

Trial Registration $₫$ Trials UMIN-CTR (University Hospital Medical Information Network Center Clinical Trials Registry), UMIN000020867 (Motion Anime DVD Intervention for Japanese Nurses), February 3, 2016.

\section{Consent to publish}

Not applicable. 
Availability of data and materials

Please contact the first author for raw data.

\section{Conflict of interests}

All authors declare no conflicts of interest.

\section{Funding}

This project was funded by the Japanese government Grants-in-Aid for Challenging Exploratory Research 2014-17 (26671047) to Mariko Nishikawa, RN, MPH. The funders had no role in study design, data collection and analysis, decision to publish, or preparation of the manuscript. The views expressed are those of the authors, whom were employed by their affiliated universities.

\section{Authors' contributions}

MN and MY jointly designed and developed the study, MY maintained the digital cartoon, MN carried out the data collection. MN and AS analyzed the data. MN, MY, JK, AS and MJ wrote the manuscript. All authors regularly reviewed manuscript drafts and approved the final version.

\section{Acknowledgements}

The authors would like to thank all nurses who participated to this study. We thank Midori lkegame, Michiko Shimoda and Ayami Kondo for helping with both the 1st intervention and 2nd intervention samplings.

\section{References}

1. World Bank Group: International tourism, number of departures 2019.

https://data.worldbank.org/indicator/ST.INT.DPRT?locations=AL Accessed 28 May 2020.

2. JNTO: Visitor arrivals by country/ aria \& purpose of visit for Jan.-Dec. 2019 (provisional figures). https://www.jnto.go.jp/jpn/statistics/since2003_visitor_arrivals.pdf (2020). Accessed 28 May 2020.

3. The Ministry of Justice: Immigration Control of Japanese and Foreign Nationals http://www.moj.go.jp/content/001285947.pdf (2019). Accessed 9 March 2019.

4. Hainsworth T. Travel health: reducing the preventable risks. Nursing times. 2002; 98(29):35-37.

5. Yamagishi S, Sakuma Y, Miyauchi K, Matsumoto A, Horikawa S, Shibui Y, et al. The anxiety for medical services system in inbound tourists to Japan. J Int Health. 2008; 23(4):273-279, [in Japanese].

6. Matsuda N, Naito T, Uehara Y, Hisaoka T. Reasons for Outpartient Visits by Foreign Travellers to an Urban hospital in Tokyo. The 14th Conference of the Int Soc Travel Med, Quebec, Canada. 2015. 
7. Osegawa M, Morio H, Nomoto K, Nishizawa M, Sadahiro T. Present medical practice and problems in emergency disease in foreign travelers requiring admission. Japan Emergency Med J. 2002; 13(11):703-710, [in Japanese].

8. Murakoshi H, Asano Y, Iwase T, Akanuma M. Five year trend in diseases contracted by nonJapaneses travelers of airport. Jpn Soc Aerosp Environ Med. 2011; 48(4):75, [in Japanese].

9. Porthe V, Vargas I, Ronda E, Malmusi D, Bosch L, Vazquez ML. Has the quality of health care for the immigrant population changed during the economic crisis in Catalonia (Spain): Opinions of health professionals and immigrant users. Gaceta sanitaria. 2018; 32(5):425-432.

10. Batista R, Pottie K, Bouchard L, Ng E, Tanuseputro P, Tugwell P. Primary health care models addressing health equity for immigrants: a systematic scoping review. J Immigr Minor Health. 2018; 20(1):214-230.

11. Zamora ER, Kaul S, Kirchhoff AC, Gwilliam V, Jimenez OA, Morreall DK, et al. The impact of language barriers and immigration status on the care experience for Spanish-speaking caregivers of patients with pediatric cancer. Pediatr Blood Cancer. 2016; 63(12):2173-2180.

12. Cheraghi MA, Manookian A, Nasrabadi AN. Human dignity in religion-embedded cross-cultural nursing. Nursing ethics. 2014; 21(8):916-928.

13. Richter J, Eisemann MR, Bauer B, Kreibeck H, Astrom S. Decision-making in the treatment of elderly people: a cross-cultural comparison between Swedish and German physicians and nurses. Scandinavian journal of caring sciences. 2002; 16(2):149-156.

14. Ho YY. Investigating internationally educated Taiwanese nurses' training and communication experiences in the United States. J Cont Educ Nurs. 2015; 46(5):218-227.

15. Casillas A, Paroz S, Green AR, Wolff H, Weber O, Faucherre F, et al. Cultural competency of healthcare providers in a Swiss University Hospital: self-assessed cross-cultural skillfulness in a crosssectional study. BMC medical education. 2014; 14:19.

16. Nishikawa M, Niiya K, Kimura M. Addressing practical issues related to nursing care for international visitors to Hiroshima. Revista da Escola de Enfermagem da U S P. 2014; 48(2):299-307.

17. Suk MH, Oh WO. Factors affecting the cultural competence of visiting nurses for rural multicultural family support in South Korea. BMC Nursing. 2018; 17:1.

18. Gasiorek J, van de Poel K. Language-specific skills in intercultural healthcare communication: Comparing perceived preparedness and skills in nurses' first and second languages. Nurse education today. 2018; 61:54-59.

19. Aboul-Enein $\mathrm{BH}$, Aboul-Enein $\mathrm{FH}$. The cultural gap delivering health care services to Arab American populations in the United States. Journal of cultural diversity. 2010; 17(1):20-23.

20. Olsen C, Conway J, DiPrete-Brown L, Hutchins F, Poulsen K, Solheim K, et al. Advancing integrative "one-health" approaches to global health through multidisciplinary, faculty-led global health field courses. Lancet Glob Health. 2015; 3:S6.

21. Tuohy D, Graham MM, Johnson K, Tuohy T, Burke K. Developing an educational dvd on the use of hand massage in the care of people with dementia: An innovation. Nurse education in practice. 2015; 
15(4):299-303.

22. Biran A, Schmidt W-P, Varadharajan KS, Rajaraman D, Kumar R, Greenland K, et al. Effect of a behaviour-change intervention on handwashing with soap in India (SuperAmma): a clusterrandomised trial. Lancet Glob Health. 2014; 2(3):e145-e154.

23. Smith CA, Chang E, Gallego G, Balneaves LG. An education intervention to improve health literacy and decision making about supporting self-care among older Australians: a study protocol for a randomised controlled trial. Trials. 2017; 18(1):441.

24. Patel N, Stone MA, Hadjiconstantinou M, Hiles S, Troughton J, Martin-Stacey L, et al. Using an interactive DVD about type 2 diabetes and insulin therapy in a UK South Asian community and in patient education and healthcare provider training. Patient education and counseling. 2015; 98(9):1123-1130.

25. Nishikawa M, Niiya K, Okayasu M, Yamanaka M. Concerning Visits to a Hospital among Foreign Visitors in Japan: Creating an Anime Multiple-language DVD Jpn Soc Prodigital Science. 2013, [in Japanese],

26. Nishikawa M, Yamanaka M, Kiriya J, Jimba M. Providing Japanese health care information for international visitors: digital cartoon intervention. BMC Health Services Research. 2018; 18(1):373.

27. Kobe Kaisei Hospital, Introduction of Hospital. https://www.kobekaisei.org/about/director_message/ (2019). Accessed 27 May 2020.

28. Macmillan AK, Mackie H, Hosking JE, Witten K, Smith M, Field A, et al. Controlled before-after intervention study of suburb-wide street changes to increase walking and cycling: Te Ara Mua-Future Streets study design. BMC public health. 2018; 18(1):850.

29. Rowthorn C, Bender A, Crawford L, Holden T, McLachlan C, Milner R, et al. Japan-Lonely planet travel guide. Lonely Planet. 2011:744-745.

30. Spielberger CD, Gorssuch RL, Lushene PR, Vagg PR, Jacobs GA. Manual for the State-Trait Anxiety Inventory. Consulting Psychologists Press. 1983.

31. Draffin CR, Alderdice FA, McCance DR, Maresh M, Harper R, Patterson CC, et al. Impact of an educational DVD on anxiety and glycaemic control in women diagnosed with gestational diabetes mellitus (GDM): A randomised controlled trial. Diabetes research and clinical practice. 2017; 126:164171.

32. Flaherty GT, Chen B, Avalos G. Individual traveller health priorities and the pre-travel health consultation. Journal of travel medicine. 2017; 24(6).

\section{Tables}

Due to technical limitations, table 1, 2, 3 and 4 is only available as a download in the Supplemental Files section.

\section{Figures}




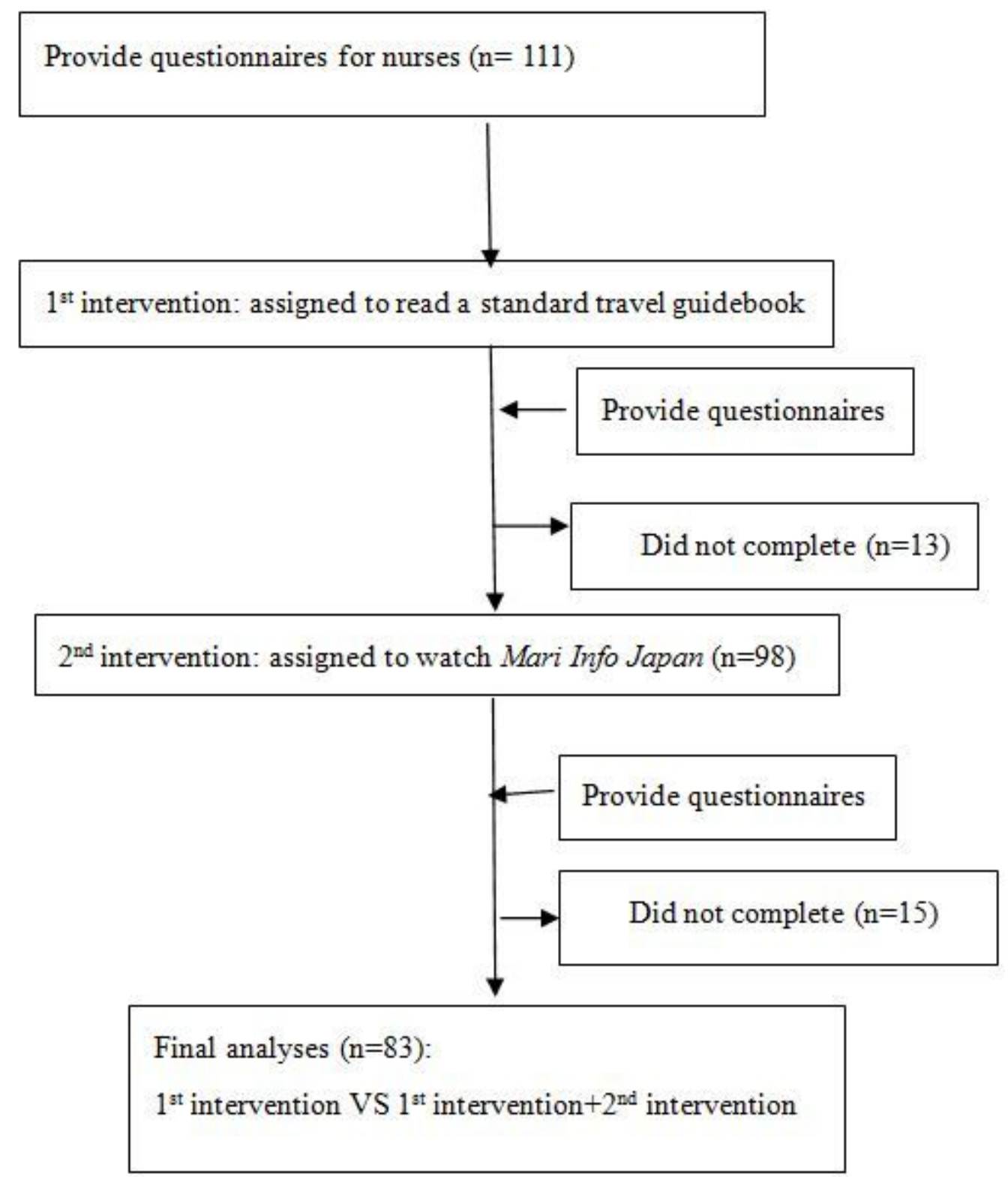

Figure 1

Trial profile

\section{Supplementary Files}

This is a list of supplementary files associated with this preprint. Click to download.

- nursetable1917.xls

- nursetable234917.xls

- Add1 informationinter.doc

- Add2MarilnfoJapan.wmv 
- Add3SurveyNurseBMC.docx

- CONSORT2010Checklist.doc 